\title{
The development of prototyping and their research over the centuries
}

Emilia BURCHARDT

DOI: 10.30464/jmee.2020.4.4.309

Cite this article as:

Burchardt E., The development of prototyping and their research over the centuries. Journal of Mechanical and Energy Engineering, Vol. 4(44), No. 4, 2020, pp. 309-314

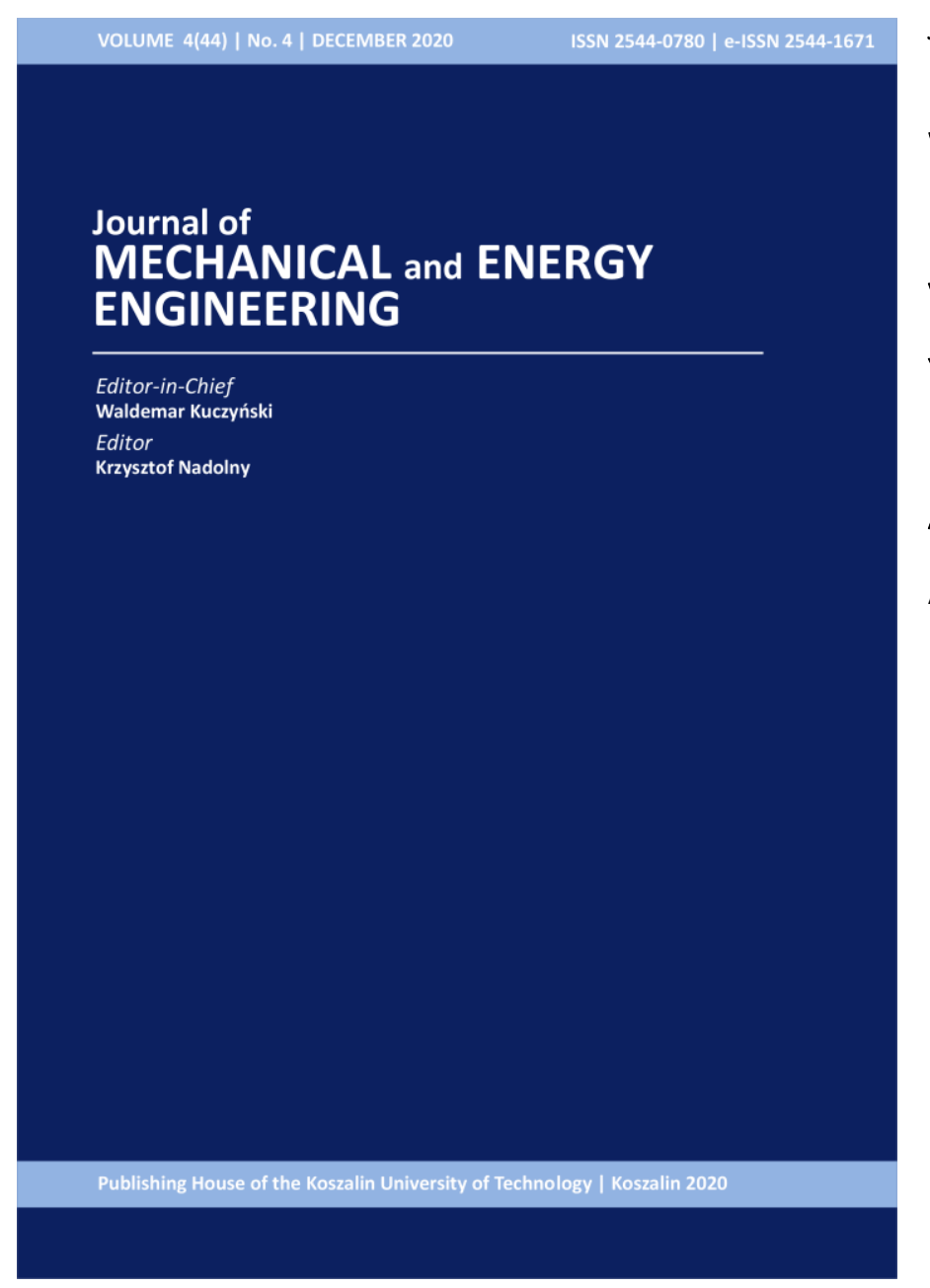

Journal of Mechanical and Energy Engineering

Website: jmee.tu.koszalin.pl

ISSN (Print): 2544-0780

ISSN (Online): 2544-1671

Volume: 4(44)

Number: 4

Year: 2020

Pages: $309-314$

\section{Article Info:}

Received 2 November 2020

Accepted 15 December 2020

\section{Open Access}

This article is distributed under the terms of the Creative Commons Attribution 4.0 (CC BY 4.0) International License (http://creativecommons.org/licenses/by/4.0/), which permits unrestricted use, distribution, and reproduction in any medium, provided you give appropriate credit to the original author(s) and the source, provide a link to the Creative Commons license, and indicate if changes were made. 


\title{
THE DEVELOPMENT OF PROTOTYPING AND THEIR RESEARCH OVER THE CENTURIES
}

\author{
Emilia BURCHARDT ${ }^{1 *}$ \\ ${ }^{1 *}$ Faculty of Mechanical Engineering, Department of Production Engineering, Koszalin University of \\ Technology, Raclawicka 15-17, 75-620 Koszalin, Poland, e-mail: emilia.gierszewska@wp.pl
}

(Received 2 November 2020, Accepted 15 December 2020)

\begin{abstract}
This paper presents issues related to the subject of prototyping. It discusses the essence of creating prototypes in historical times and in contemporary times. The paper presents the process of car development in the times of Henry Ford and in modern times. Briefly contemporary methods of prototyping, so-called fast prototyping methods, are discussed. In short, the issues of researching prototypes in historical and contemporary times are also discussed. This article perfectly allows to see the progress in technology that has been made over the centuries from XIX to XXI.
\end{abstract}

Keywords: prototype, testing prototypes, rapid prototyping, new product, implementation

\section{INTRODUCTION}

Progress and development have been an inseparable sequence of things from an early age. It takes place at all levels of life. Over the following millennia, man has evolved as a living figure, animals, industrial revolutions have taken place, new continents, raw materials and materials have been discovered. Research has been and continues to be carried out, contributing to the development of certain spheres of life. Research people take part in the race to discover as soon as possible a novelty that will have a significant impact on the life and functioning of the world. The same applies to engineering. Man is constantly looking for new solutions that would improve or enhance the quality of life and work. New methods or devices have always been created on the principle of creating many attempts and then making corrections to improve.

This article presents how the understanding and meaning of the word prototype has changed over the centuries. The methods of testing prototypes in modern times are also discussed briefly.

\subsection{The concept of prototyping}

To talk about the development of prototyping, you need to understand the concept of the word. Nowadays there are many definitions of the word prototype.
However, the simplest way to translate a prototype is the first one made according to the document-related model of a machine or device. This model is the basis for starting serial production.

Referring to the definition of the Polish language dictionary, the prototype is called "the first copy of something, made according to the prepared document-issue, on which tests and studies are carried out in order to check the correctness of the documentation and its functioning before the start of serial production" [9].

\subsection{The essence of prototyping}

Creating prototypes is an extremely important stage in the process of developing a new product. During prototype construction, new ideas are put into practice for the first time. The purpose of making a prototype is to verify the correctness of the developed documentation, and also allows to supplement the documentation with details impossible to predict without physical execution. The purpose of creating prototypes is to check them for realized construction solutions. The prototype also allows to check such features as: functionality, usability, safety [6]. 


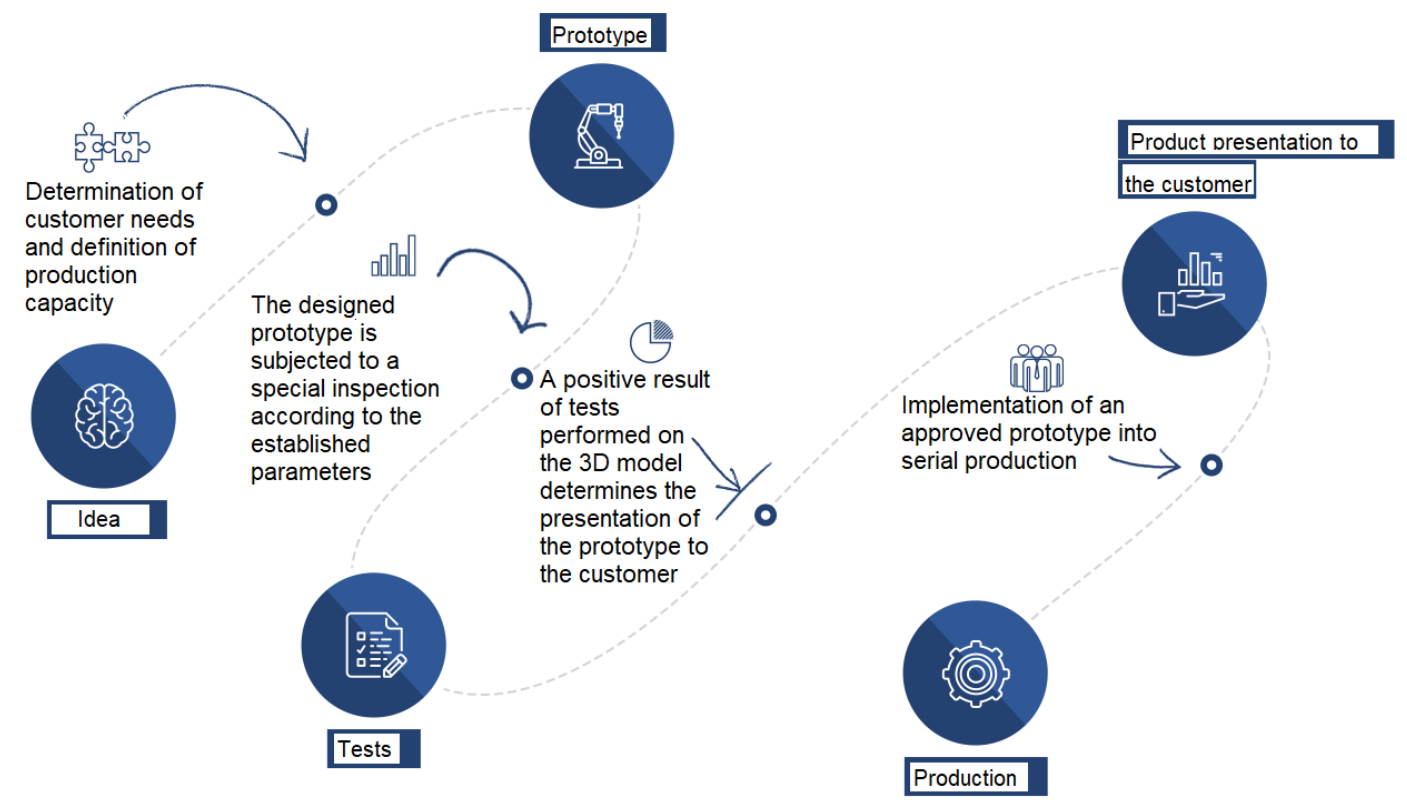

Fig. 1. The essence of prototyping [8]

Tests carried out on prototypes allow to analyze the behavior of products in real conditions and then, if necessary, improve the product [4].

In the past, the purpose of creating a prototype was to help develop a marketable product. Today, a prototype is created in order to verify.

The system is used for the presentation of the requirements, testing of technical solutions, detection of faults, as well as for the presentation of the progress of work. After building the prototype, which fully meets the requirements, the construction of the final device is started.

\section{CREATING PROTOTYPES IN HISTORICAL AND MODERN TIMES}

Creating prototypes, although unaware of the creators, existed already in ancient times. An example of such a prototype can be a circle. The first wheel, created to facilitate transportation, was created in the middle of the fourth century BC. Comparing its construction with the construction of a modern wheel, it was the first prototype of a wheel that we know today. For many years it was used for transport, tested and improved until the wheel was made as we know it today.

The history of the wheel's development is shown in Figure 2. It can be perfectly observed that the first wheels were wooden, filled in the middle, which made them more resistant when driving on unpaved roads. Improved wheels, although they were still wooden, already had spokes and empty spaces between them. As a result, e.g., gravel on the road was pouring through and constituted less resistance during the wheel movement.

The appearance of the wheel we use nowadays, apart from its shape, does not resemble the original one. Modern wheels consist of a steel rim and a rubber tire surrounding it.

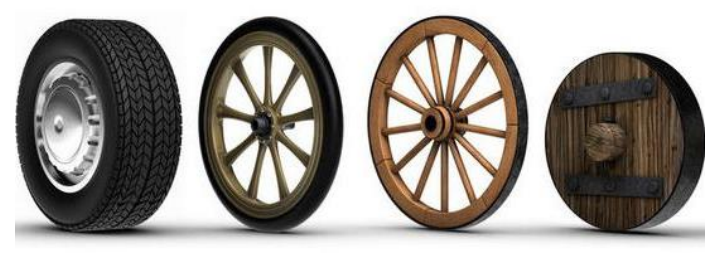

Fig. 2. Wheel history [10]

In the past, creating a prototype was preceded by long, hand-made calculations.

Nowadays, the process of creating prototypes is improved by computer tools and software, which can be used to observe the behavior of the prototype in real conditions.

\subsection{The beginnings of prototyping}

Prototyping in the twentieth century was a complicated procedure. Each part was performed with the greatest care, using human hands and tools available at the time.

The constructors made each part separately and then worked on the subsequent parts. Figure 3 shows the first prototype car. It is a car created in 1870 by Siegfried Marcus. It was a mechanical vehicle with a petrol spark-ignition engine. 


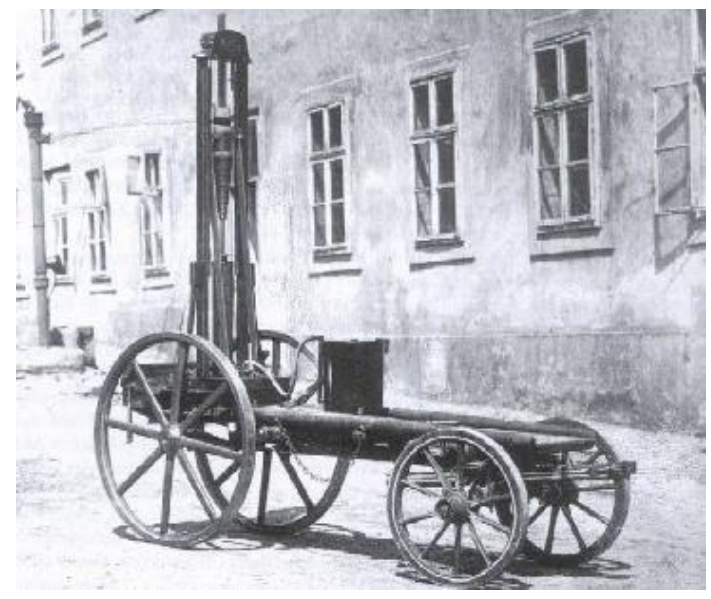

Fig. 3. 1870 car prototype [12]

Figure 4 shows a vehicle powered by a petrol engine. It was also built by Siegfried Marcus. It was the first vehicle with all the features of a motor vehicle. It is the oldest car in the world, fully capable of driving. The car can still be seen in the Museum of Technology in Vienna [11].

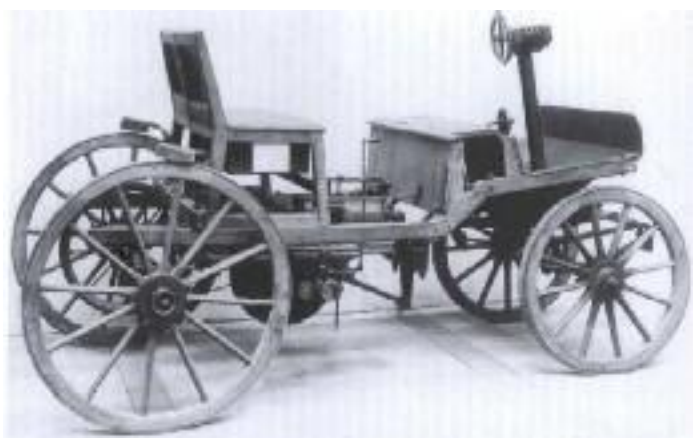

Fig. 4. Improved prototype from 1888 [12]

This car had a cubic capacity of $1570 \mathrm{~cm}^{3}$ and its power was about 0.75 horsepower. The speed it could reach was about $6-8 \mathrm{~km} / \mathrm{h}$. It was a heavy vehicle made of iron and wood. In this car the wheels were spoke, wooden. The engine ignition was magnetoelectric, four-stroke, extremely advanced for the conditions of the time.

\subsection{Creating new products in historical times}

The creation of new products in historical times can be perfectly illustrated by the example of a car.

As you can see, in historical times the process of developing a new product was a very timeconsuming one. It often took several years to produce one car, which was then tested and improved. Nowadays such a practice is impossible to implement. The competition forces us to develop a new product as quickly as possible. Acting as it was in historical times, it would lead to the fact that before the manufacturer would introduce its product, the competition would already introduce one new, improved product, which would be more successful among consumers.

We can say that the cars produced in the times of Henry Ford were prototypes of the cars we know today.

The production of a new car often lasted several years. It can be perfectly observed on the example of the car created by Siegfried Marcus. The first car was created in 1870. After the tests, it started to improve the car, and the next one was not created until 1888.

Henry Ford also developed his first vehicle for several years. During this time, no endurance tests were carried out, no prototype was created to check the vehicle from the ergonomic and chemical point of view. It can be said that the first prototype was at the same time a prototype car, the test of which took place at the moment of the first car ride. This can be proved by the fact that Henry Ford encountered a serious problem after finishing work on the car. The car he produced was too big to fit in the garage door, as a result of which part of the wall had to be demolished in order to take the vehicle outside [2].

In historical times, individual car components were manufactured using craft methods. At that time, there were no lathes or numerical milling machines. There was no software to perform computer simulations. The car project was developed on paper. The greatest success was the fact that the vehicle started at all. The realization of such projects was very time and costconsuming, but nobody was sure if the produced vehicle would start at all and go even a few meters.

\subsection{Modern prototyping}

Nowadays the process of creating prototypes is much shorter than in historical times. Time to produce a new car "from the idea to industry" is about 4 years. Before a physical model of a car, equipped with the necessary components, is developed, a concept model is developed. This is the so-called first prototype. Very often it is made of clay. The model of the new Audi is shown on the Figure 5.

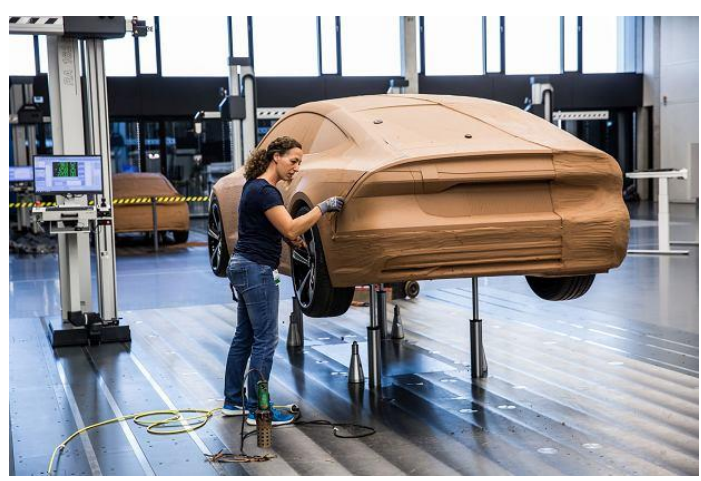

Fig. 5. Audi A7 model made in clay [13]

At this stage, you get a 1:1 scale model that can be analyzed in terms of design. It is also possible 
to place stickers to replace tires, windows or bodywork. Already at this stage it is possible to make design adjustments [13].

After this stage, a physical model of the car is made, in which many components, e.g., the body can be made on 3D printers. This process is much less expensive than making a real car body. Nowadays, the prototyping process is mainly based on rapid prototyping techniques.

The use of new prototyping methods, so called Rapid Prototyping, not only allows to shorten the time of prototype development, but also allows to significantly reduce the necessary expenses: costs, materials, human resources.

Rapid prototyping techniques are a relatively young field, as they come from the second half of the 20th century. As some sources say, the development of rapid prototyping techniques was significantly influenced by such areas as topography and photo sculpting [3].

The most popular methods of creating prototypes used nowadays include: Rapid Prototyping, Reverse Engineering, Rapid Tooling, Virtual Reality.

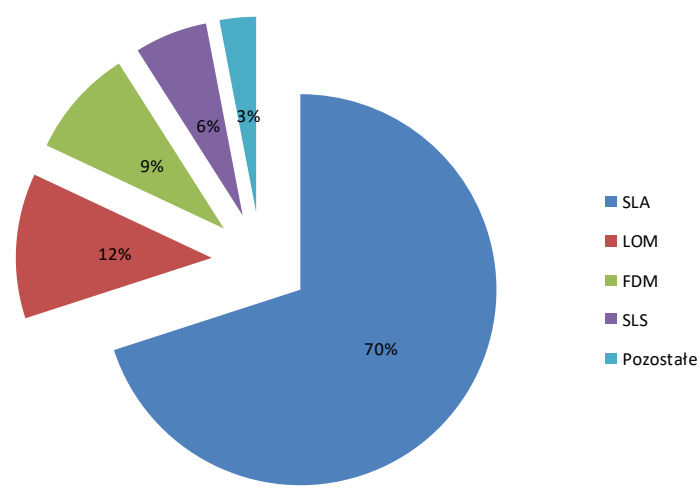

Fig. 6. Participation of individual methods of rapid prototyping [1]

Rapid prototyping is a method that is very popular in the process of creating prototypes. It is creating prototypes using incremental methods. The basis of fast prototyping is a $3 \mathrm{D}$ model of the produced elements In the process of fast prototyping, this model is converted to the STL format and then it is divided into individual layers. In the following stages, with the use of predictive devices, a physical model is created from individual layers [4]. Figure 6 shows the contribution of individual rapid prototyping methods to the prototype creation process. It can be clearly seen that the most popular method is the SLA method - stereolithography, in which the polymer resin is usually hardened with a laser beam. This way, layer by layer, the designed model is created.

Reverse engineering is a method that was developed before the implementation of modern computer support techniques. Then, with the use of conventional measurement methods, data was collected, on the basis of which executive documentation was developed. After the appearance of measuring machines, it was possible to collect a significant number of $3 \mathrm{D}$ points, because of which a computer model of a given object was created [7]. This method is particularly popular among creators, who are familiar with creating physical models from materials susceptible to forming such as clay and gypsum.

Rapid tooling, these are techniques used to develop a product that has previously been manufactured using fast prototyping methods. Fast tool making methods are used to give prototype models the characteristics of the finished product. This feature can be the use of the right material. The RT method is also used to develop tools, used to produce small series of new products [1].

\section{PROTOTYPE TESTING}

Prototype testing is an essential stage in the process of developing a new product. It allows to answer the question whether a new product meets all the design assemblies, whether it is functional, whether it meets the requirements in terms of ergonomics, etc. This is an extremely important stage, which must be carried out in an accurate manner, but it is constantly striving to make this stage shorter and shorter in the whole process of developing a new product.

In historical times the testing of prototypes differed significantly from modern methods of testing prototypes. At that time, it was customary for a designer to use a given product for private purposes. Testing took place as the product was used.

This can be perfectly observed on the example of the car constructed by Henry Ford. In June 1896 he made his first drive in a car he constructed a quadrilateral. The vehicle was moving at a speed of about $15 \mathrm{~km} / \mathrm{h}$. It was largely a wooden car, but had wheels, axles and a metal engine. However, it drove only a few minutes and then, due to an ignition spring malfunction, it come to stop.

After the first attempt to drive, Ford knew what he had to improve in the car and after a few years he produced two more prototypes which he subjected to various tests, starting in rallies. These constant tests and the construction of better and better vehicles led Henry Ford to present the Ford model T to the world in 1908. The premiere of this car is considered to be the beginning of mass motorization [2]. Nowadays, the process of developing and testing a car is much shorter and does not require the constructors to produce many copies of prototypes. The process of developing a new product on the example of a passenger car is shown in Figure 7. This process is much faster than in the times of Henry Ford. The modern prototype of the self-drive can consist of both parts produced in a conventional way and those produced using incremental methods. The first prototype testing takes place already at the 
stage of car design, when strength tests can be performed using computer software.

Nowadays, the functionality and ergonomics of a vehicle is tested using computer methods such as virtual reality. This method allows to move in a three-dimensional computer space. In this space, product models and their features are presented, production simulations as well as production planning and control. This technique gives the possibility of performing many simulations and then allows you to choose the best version that will be implemented into production. The essence of virtual prototyping is to create virtual reality by mapping the real world in which the new product will work. Designing virtual reality is the turning point of virtual prototyping. This reality allows to explore not only one particular product, but the whole family of products. This fact greatly facilitates the work on a new product [5].

The introduction of virtual reality methods in the process of testing prototypes has contributed to a huge progress in the process of developing a new product.

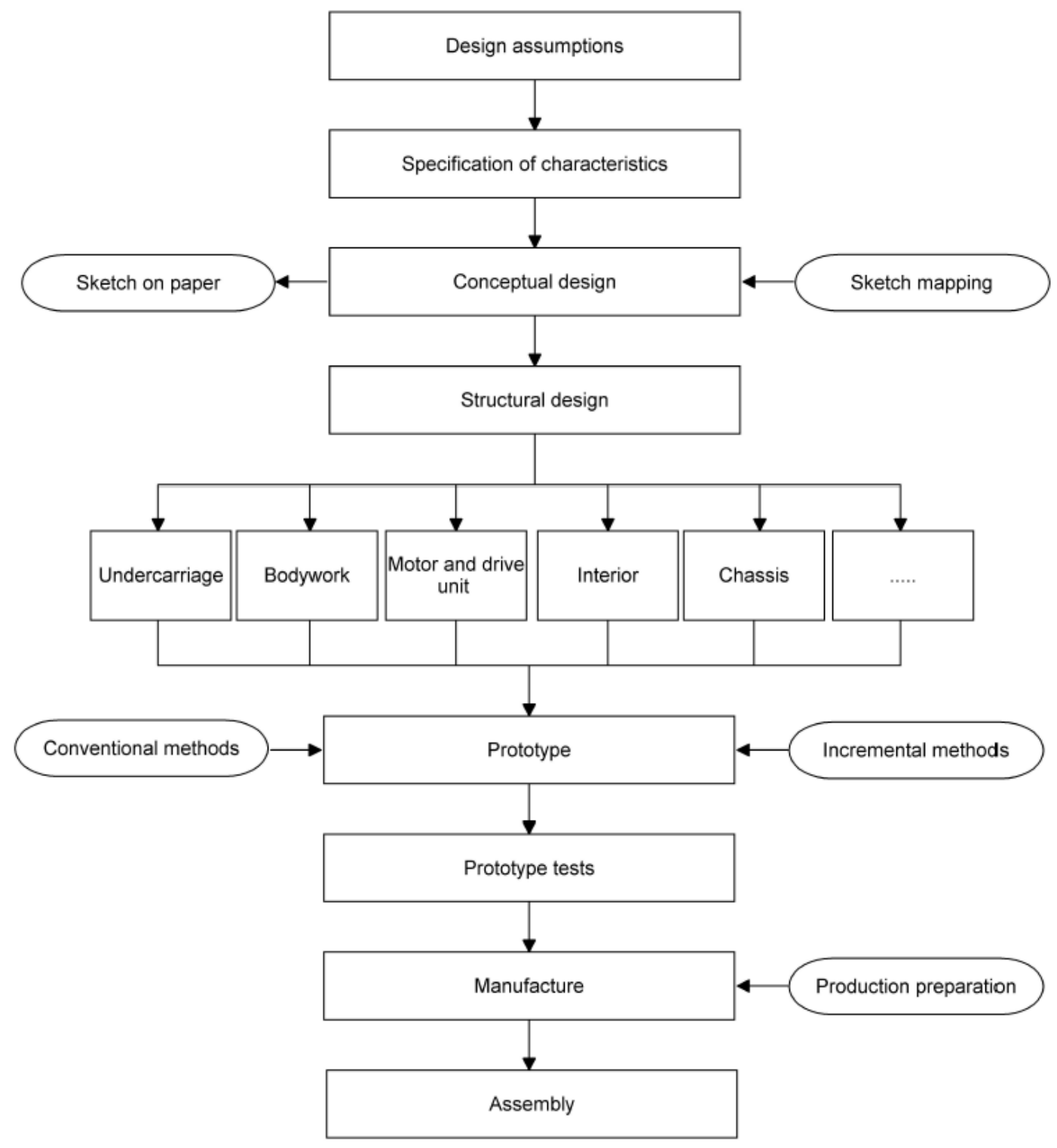

Fig. 7.Procedure of developing an innovative product on the example of a vehicle [4] 


\section{CONCLUSIONS}

This article presents issues related to the creation and testing of new product prototypes. It discusses the process the creation of a new product in the 19th century. The product on the basis of which the presentation was made was the first car. In the further part of the work the process of car development in modern times was presented. From the above article the following conclusions can be worked out:

1. The constant development of the world contributes to the search for newer and better solutions. This can be perfectly observed on the example of a car.

2. In the 19th century, the process of developing a new car was as time-consuming as it was costly.

3. In historical times, it was necessary to build a car first and then to carry out tests on a physical model. In such a model, each of the elements was made with the greatest care.

4. The actual tests allowed to answer the questions if the vehicle meets all the requirements. Whether it is ergonomic. The tests also provided information on what needs to be improved and then new, improved models were created.

5. In modern times, the process of developing a new car is much shorter and the costs of prototyping are kept to a minimum.

6. Nowadays, the prototype is built using fast prototyping methods, which significantly accelerate the process of model building.

7. Tests of the prototype are carried out already in the design phase of the car. This is done using computer software and virtual reality.

\section{References}

1. Chlebus E., 2000, CAx computer techniques in production engineering, WNT, Warsaw (pp. 25-26, 240-245, 248257) (in Polish).

2. Liebfeld Alfred, Henry Ford, legend and reality, Book and Knowledge, Warsaw, 1970 (in Polish).

3. Otto K., Wood K., Product Design, Techniques in Reverse Engineering and New Product Development, Prentice Hall, New Jersey 2001.

4. Plichta J, Plichta S., Computer Techniques in Production Engineering, Koszalin University of Technology Publishing House, 2006, (in Polish).

5. Sztkowski K. and other, Modern Production Management, Process Sharing, PWN, Warsaw 2014 (in Polish).

6. Sojkin B., Product Management, PWE, Warsaw 2003, (in Polish).

7. Wang J., Gu D., Yu Z., Tan Ch., Zhou L., A framework for $3 \mathrm{D}$ model reconstruction in reverse engineering, Computers \& Industrial Engineering, No.63, 2012.

8. http://pass.com.pl/inzynieria-produktu/ (accessed: April/May 2020).

9. http://sjp.pl/prototyp, 2015 (accessed: April 2020)

10. http://nextews.com/920711c9/ (accessed: April/May 2020).

11. https://www.technischesmuseum.at/objekt/marcuswagen-1888-1889 (accessed: April 2020).

12. https://pl.wikipedia.org/wiki/Siegfried_Marcus (accessed: April/May 2020).

13. https://moto.pl (accessed: May 2020).

\section{Biographical note}

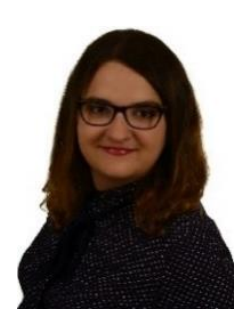

Emilia Burchardt received her B.Sc. degree in Management and Production Engineering from the Faculty of Mechanical Engineering at the Koszalin University of Technology in 2016. Her scientific interests focus on problems concerning implementation of innovative processes and products, rapid prototyping and reverse engineering methods as well as abrasive machining processes. She has presented the results of her work in one international and three national conferences. She is an author and a coauthor of 8 scientific papers in conference proceedings. 